\title{
Improvement in exercise capacity after a modified Potts shunt in an adult patient with pulmonary arterial hypertension
}

\begin{tabular}{|c|c|}
\hline $\begin{array}{l}\text { Copyright @The authors } 2021 \\
\text { This version is distributed under } \\
\text { the terms of the Creative } \\
\text { Commons Attribution Non- } \\
\text { Commercial Licence 4.0. For } \\
\text { commercial reproduction rights } \\
\text { and permissions contact } \\
\text { permissions@ersnet.org } \\
\text { Received: } 26 \text { April } 2021 \\
\text { Accepted: } 13 \text { July } 2021\end{array}$ & To the Editor: \\
\hline (c) (c) & 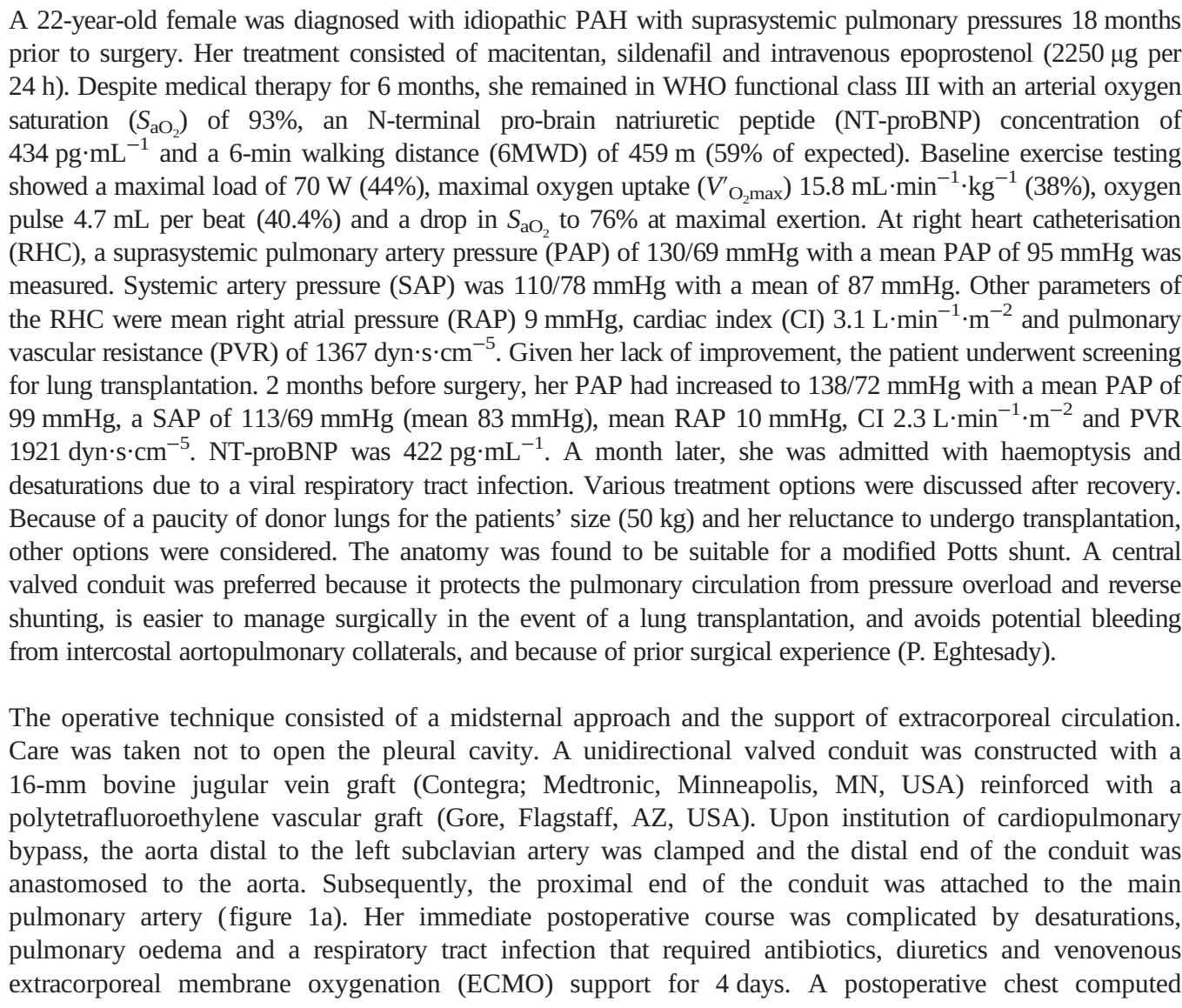 \\
\hline $\begin{array}{l}\text { W } \\
\text { Check for } \\
\text { updates }\end{array}$ & $\begin{array}{l}\text { Shareable abstract (@ERSpublications) } \\
\text { For young adults with end-stage idiopathic pulmonary hypertension, a valved graft connecting the } \\
\text { central pulmonary artery to the distal aortic arch can provide substantial palliation of symptoms } \\
\text { and may defer lung transplantation https://bit.ly/2TVMFFC }\end{array}$ \\
\hline & $\begin{array}{l}\text { Cite this article as: Symersky P, Jansen SMA, Kamminga SK, et al. Improvement in exercise capacity } \\
\text { after a modified Potts shunt in an adult patient with pulmonary arterial hypertension. ERJ Open Res } \\
\text { 2021; 7: 00287-2021 [DOI: } 10.1183 / 23120541.00287-2021 \text { ]. }\end{array}$ \\
\hline
\end{tabular}



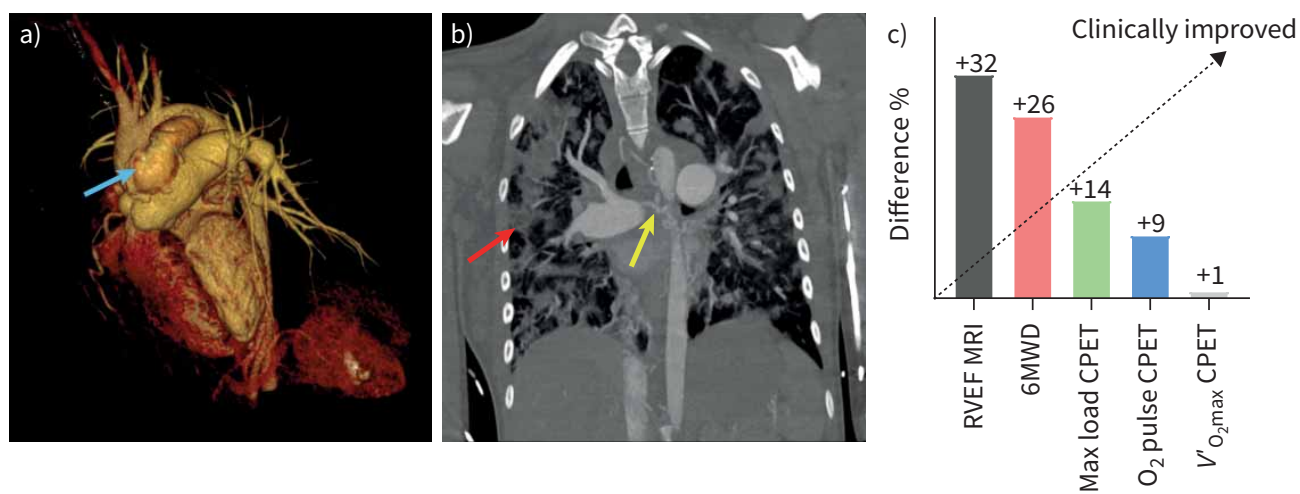

FIGURE 1 a) Three-dimensional image of the Potts shunt (blue arrow) using Volume Rendering Technique. The proximal end of the conduit was attached to the main pulmonary artery and the distal end was anastomosed to the aorta. b) Pulmonary oedema (red arrow) after Potts shunt procedure originated from large collateral bronchial vessels (yellow arrow). Coronal chest computed tomography image with a maximal intensity projection of $3 \mathrm{~mm}$. c) Per cent difference in right ventricle ejection fraction (RVEF), 6-min walking distance (6MWD), maximal (max) load during cardiopulmonary exercise testing (CPET), oxygen pulse during CPET and maximal oxygen uptake $\left(V_{\mathrm{O}_{2} \max }^{\prime}\right)$ during CPET. Per cent difference measured between 1 month prior to surgery and 1 year after surgery. MRI: magnetic resonance imaging.

tomography showed large aortopulmonary collateral vessels as a possible source for the pulmonary oedema (figure 1b). She was weaned from the ventilator on the 15th day postoperatively. Intravenous epoprostenol was tapered from the eighth postoperative day and substituted for the oral prostacyclin receptor agonist selexipag (1200 mg twice daily) 1 month postoperatively.

1 year after surgery, her exercise tolerance was measured (figure 1c). Maximal load was improved to $80 \mathrm{~W}$ (53\%), $V_{\mathrm{O}_{2} \max }^{\prime}$ was $16 \mathrm{~mL} \cdot \mathrm{min}^{-1} \cdot \mathrm{kg}^{-1}(41 \%)$ and oxygen pulse $5.1 \mathrm{~mL}$ (45.2\%). Her 6MWD had increased to $580 \mathrm{~m}$ (75\%). She was WHO functional class II, could climb a flight of stairs and swim, and had resumed work. NT-proBNP was decreased to $206 \mathrm{pg} \cdot \mathrm{mL}^{-1}$. Cardiac magnetic resonance imaging (MRI) 1 month prior to surgery and 1 year after surgery showed significant improvement: the right ventricular end-diastolic volume (EDV) was unchanged (138 compared to $137 \mathrm{~mL}$ ), end-systolic volume (ESV) decreased from 86 to $68 \mathrm{~mL}$ and ejection fraction improved from $38 \%$ to $50 \%$. The left ventricle EDV rose from 92 to a mildly dilated $121 \mathrm{~mL}$, while the ESV rose from 31 to $51 \mathrm{~mL}$. The left ventricular ejection fraction decreased mildly from $66 \%$ to $58 \%$.

The improvement of exercise tolerance attests to the fact that a modified unidirectional Potts shunt may provide palliation of symptoms in adult patients with PAH. Walking distance (6MWD) improved most, with a more modest increase in maximal load and $V^{\prime}{ }_{\mathrm{O}_{2} \max }$. Quality of life improved impressively and the patient remains in functional class II despite tapered medication. Several observations may be significant. First, the follow-up with MRI demonstrated a dilatation of the left ventricle and concomitant drop in left ventricular ejection fraction 1 year post-shunt. This is a novel observation and may have to be confirmed by other studies. Whether this remodelling improves or not requires further follow up. Possibly, older patients may adapt more slowly to the abrupt change in physiology caused by the modified Potts shunt. Similarly, the use of postoperative venovenous ECMO support in paediatric patients was rare compared to $80 \%$ in a recent series of older patients [5]. Another observation particular to this patient was the presence of aortopulmonary collateral vessels. These collaterals can occur in 15-30\% of patients with idiopathic pulmonary hypertension and are the primary reason for haemoptysis requiring embolisation [7]. Presently, it is not known how the presence of the Potts shunt physiology interacts with existing collaterals. Historically, however, the development of such collaterals secondary to relative hypoxia was well described in the era of applying Potts shunt for the palliation of so-called blue babies, such as the Tetralogy of Fallot [8]. Given the inevitable diversion of pulmonary blood flow, the presence of large systemic collaterals may be a risk factor for postoperative pulmonary oedema as seen in this patient. In addition, collaterals may pose a considerable surgical challenge with an approach through a left thoracotomy. Opening the pleural space with collapse of the lung may cause tears of the collaterals emerging from the intercostal vessels with possibly intractable bleeding. A midsternal approach leaves the pleural space intact and avoids bleeding from these friable collaterals. 
In summary the promising results of the modified Potts shunt need to be confirmed in more adult patients, but the first experience may help to pave the way for a broader use of these shunts in this specific population of patients.

Petr Symersky $\oplus^{1,2}$, Samara M.A. Jansen ${ }^{3}$, Suzanne K. Kamminga ${ }^{4}$, Lilian J. Meijboom ${ }^{5}$, Erik J. Lust ${ }^{6}$, Pirooz Eghtesady $\mathbb{0}^{7}$, Robert M. Grady ${ }^{1}$ and Harm J. Bogaard ${ }^{3}$

${ }^{1}$ Dept of Cardiothoracic Surgery, Amsterdam UMC, Vrije Universiteit, Amsterdam, the Netherlands. ${ }^{2}$ Dept of Cardiothoracic Surgery, OLVG Hospital, Amsterdam, the Netherlands. ${ }^{3}$ Dept of Pulmonology, Amsterdam UMC, Vrije Universiteit, Amsterdam, the Netherlands. ${ }^{4}$ Dept of Anesthesiology, Amsterdam UMC, Vrije Universiteit, Amsterdam, the Netherlands. ${ }^{5}$ Dept of Radiology and Nuclear Medicine, Amsterdam UMC, Vrije Universiteit, Amsterdam, the Netherlands. ${ }^{6}$ Dept of Intensive Care, Amsterdam UMC, Vrije Universiteit, Amsterdam, the Netherlands. ${ }^{7}$ Depts of Surgery and Pediatrics, Washington University School of Medicine, St Louis, MO, USA.

Corresponding author: Petr Symersky (p.symersky@olvg.nl)

Provenance: Submitted article, peer reviewed.

Conflict of interest: None declared.

\section{References}

1 Blanc J, Vouhé P, Bonnet D. Potts shunt in patients with pulmonary hypertension. N Engl J Med 2004; 350: 623.

2 Baruteau AE, Belli E, Boudjemline $\mathrm{Y}$, et al. Palliative Potts shunt for the treatment of children with drug-refractory pulmonary arterial hypertension: updated data from the first 24 patients. Eur $J$ Cardiothorac Surg 2015; 47: e105-e110.

3 Aggarwal M, Grady RM, Choudhry S, et al. Potts shunt improves right ventricular function and coupling with pulmonary circulation in children with suprasystemic pulmonary arterial hypertension. Circ Cardiovasc Imaging 2018; 11: 007964.

4 Keogh AM, Nicholls M, Shaw M, et al. Modified Potts shunt in an adult with pulmonary arterial hypertension and recurrent syncope - three-year follow-up. Int J Cardiol 2015; 182: 36-37.

5 Rosenzweig EB, Ankola A, Krishnan U, et al. A novel unidirectional-valved shunt approach for end-stage pulmonary arterial hypertension: early experience in adolescents and adults. J Thorac Cardiovasc Surg 2021; 161: 1438-1446.

6 Salna M, van Boxtel B, Rosenzweig EB, et al. Modified Potts shunt in an adult with idiopathic pulmonary arterial hypertension. Ann Am Thorac Soc 2017; 14: 607-609.

7 Remy-Jardin M, Duhamel A, Deken V, et al. Systemic collateral supply in patients with chronic thromboembolic and primary pulmonary hypertension: assessment with multi-detector row helical CT angiography. Radiology 2005; 235: 274-281.

8 Ma M, Mainwaring RD, Hanley FL. Comprehensive management of major aortopulmonary collaterals in the repair of tetralogy of Fallot. Semin Thorac Cardiovasc Surg Pediatr Card Surg Annu 2018; 21: 75-82. 